\title{
The COVID-19, Obesity, and Food Insecurity Syndemic
}

\author{
Sydney Pryor $^{1}\left[\right.$ [D $\cdot$ William Dietz $^{1}$
}

Accepted: 24 September 2021 / Published online: 9 February 2022

(c) The Author(s), under exclusive licence to Springer Science+Business Media, LLC, part of Springer Nature 2022

\begin{abstract}
Purpose of Review To introduce and provide evidence for the new Syndemic of COVID-19, Obesity, and Food Insecurity and propose strategies for mitigating its impact, particularly among vulnerable populations.

Recent Findings The COVID-19 pandemic has exacerbated obesity, food insecurity, and the existing inequities in the essential workforce. Food insecurity is driven by unsustainable dietary patterns and is associated with higher rates of obesity, which increases the risk of COVID-19 infections, hospitalizations, and deaths. The COVID-19 pandemic has disproportionately impacted the essential food supply chain workforce. Strengthening the social safety net and expanding worker protections will increase food security and secure livelihoods during and beyond the scope of the COVID-19 pandemic.

Summary Strengthening local and regional food systems provides a common solution to both the new Syndemic of COVID19, Obesity, and Food Insecurity and the Global Syndemic of Obesity, Undernutrition, and Climate Change by promoting sustainable food production and consumption, and prioritizing the food supply chain workforce.
\end{abstract}

Keywords COVID-19 $\cdot$ Obesity $\cdot$ Food insecurity $\cdot$ Syndemic $\cdot$ Sustainable food systems $\cdot$ Essential workforce

\section{Introduction}

The first of our papers [1] focused on the Global Syndemic of Obesity, Undernutrition and Climate Change [2••]. The advent of the COVID-19 pandemic spawned a second overlapping Syndemic of COVID-19, Obesity, and Food Insecurity. Like the Global Syndemic, the pandemics of COVID19 , obesity, and food insecurity occur in the same time and place, increase the adverse consequences of each, and have a disproportionate impact on underserved and vulnerable populations. The COVID-19 Syndemic has illustrated numerous vulnerabilities and disparities along the US food supply chain, from production to processing and transport, and ultimately to consumption. We focus here on how the COVID-19 pandemic exacerbated obesity, food insecurity, and disparities in the essential work force, and offer strategies to address these disparities. The promise of linking these two syndemics is that there are common solutions in

This article is part of the Topical Collection on Etiology of Obesity

Sydney Pryor

sydneypryor@gwu.edu

1 Milken Institute School of Public Health, The George Washington University, 950 New Hampshire Ave NW, Washington, DC 20052, USA the food and agriculture sector. As we did in our first paper, our solutions are specific to the US, although some may be generalizable to other countries.

\section{The Disease Burden and Interactions of COVID-19, Obesity, and Food Insecurity}

Data from 150,000 COVID-19 infected adult patients showed an increased risk and dose response effect of obesity on hospitalizations, intensive care admissions, and death [3]. Obesity was also among the most frequent diagnoses associated with COVID-19 infections in children and adolescents aged 18 years and younger [4••]. As shown in Table 1, rates of COVID-19 infection, hospitalization, and death occur more frequently in American Indians/Alaskan Natives, Blacks, and Hispanics than among whites [5]. Unlike adults, racial/ethnic differences in response to COVID-19 are not as apparent in children and adolescents [6]. The increased impact of COVID-19 on adult Black patients may be partially attributable to the increased frequency of hypertension, diabetes, obesity, and renal disease compared to white patients $[7 \bullet \bullet]$.

Several recent reports indicate that the effects of the COVID-19 pandemic have already increased the prevalence 
Table 1 Risk of COVID-19 for infections, hospitalizations, and death by among Black, American Indian/Alaskan Natives, and Hispanic/ Latino populations (CDC), compared to non-Hispanic Whites [5]

\begin{tabular}{llll}
\hline $\begin{array}{l}\text { Risk ratio compared to } \\
\text { non-Hispanic Whites }\end{array}$ & $\begin{array}{l}\text { American Indian/ } \\
\text { Alaskan Native }\end{array}$ & Black & Hispanic/Latino \\
\hline Cases & $1.6 \mathrm{X}$ & $1.1 \mathrm{X}$ & $2.0 \mathrm{X}$ \\
Hospitalization & $3.3 \mathrm{X}$ & $2.9 \mathrm{X}$ & $2.8 \mathrm{X}$ \\
Death & $2.4 \mathrm{X}$ & $1.9 \mathrm{X}$ & $2.3 \mathrm{X}$ \\
\hline
\end{tabular}

of obesity in adults and youth. A Massachusetts study examined weight gain in approximately 11,500 adults who were seen clinically before March 1 and after May 31, 2020 [8]. Clinically meaningful weight gain, defined as a gain of $\geq 5 \%$ of body weight, occurred in $29 \%$ of women and $27 \%$ of men, and was greater in 18- to- 39 -year-old adults than those $\geq 60$ years. Among those who gained $\geq 5 \%$ of their body weight, the prevalence of obesity increased by approximately $7 \%$. In a repeated cross-sectional analysis of obesity prevalence in a large sample of pediatric patients, data collected from June through December 2019 were compared to the prevalence of obesity in a sample collected from June through December 2020 [9••]. Overall, the prevalence of obesity increased from 13.7 to $15.4 \%$. Prior to the pandemic, the prevalence of obesity was approximately $10 \%$ in non-Hispanic white youth and approximately $20 \%$ among non-Hispanic Black and Hispanic youth. During the pandemic, obesity rates increased among all groups, but the gap between the prevalence of obesity in non-Hispanic whites and non-Hispanic Blacks and Hispanics increased from 10 to $11 \%$ to 13 to $14 \%$ [9••], emphasizing the disproportionate impact of the pandemic on youth of color.

The COVID-19 pandemic has also increased the frequency of food insecurity. Rates of food insecurity had already been increasing among US adults between 1999 and 2016 [10••], and disparities in the prevalence of food insecurity were already apparent. For example, data from the National Health and Nutrition Examination Survey (NHANES) between 1999 and 2000 and 2015 and 2016 indicated that the prevalence of food insecurity increased from 6 to $13 \%$ in whites but increased from 12 to $29 \%$ in Blacks and from 19 to $35 \%$ in Hispanics; the prevalence of food insecurity was highest among people with obesity $[10 \bullet \bullet]$. Although comparable NHANES data are not available, the pandemic appears to have increased the prevalence of food insecurity even further. Analyses from the Coronavirus Tracking Survey in September 2020, a nationally representative survey, assessed food insecurity in US families with 6-18-year old children [11]. Twenty-five percent of families with school aged children reported food insecurity, but among families with Black or Hispanic parents, the prevalence of food insecurity was $40 \%$ [11]. Although food insecurity in adults is associated with an increased risk of obesity [10••], data in children and adolescents demonstrate an inconsistent relationship [12].

The COVID-19 pandemic has also increased rates of physical inactivity among children and adults $[13,14]$ which likely contributed to increases in the prevalence of obesity, which in turn further increases susceptibility to COVID-19 infections and deaths. These findings are a particular concern insofar as adults infected with COVID-19 who met physical activity guidelines had reduced rates of hospitalization, ICU care, and mortality compared to inactive adults [15], all of which may have been mediated by the positive impact of physical activity on immune function [16].

The COVID-19 pandemic has also prompted a shift to ultra-processed food [17], particularly in unemployed and food-insecure families $[18,19]$. Increased consumption of ultra-processed foods by children and adolescents in food insecure families may contribute to an increased likelihood of obesity [18], again further increasing susceptibility to COVID-19 infections and deaths. Ultra-processed foods [20] are high in salt, sugar, and fat, inexpensive, tasty, and widely available and have a long shelf life. In poorer populations, reduced access to grocery stores and increased food prices may have prompted shifts to ultra-processed foods and consequent weight gain. A systematic review has demonstrated that consumption of ultra-processed foods in adults is associated with increased weight gain, obesity, waist circumference, and mortality [21]. A prospective study of children found that increased consumption of ultra-processed foods was associated with increases in their BMI trajectories [22]. These observations are supported by a recent randomized clinical trial that demonstrated increased weight gain among a group consuming ultra-processed foods over a 2-week period, whereas when the group was crossed over to an unprocessed diet, weight loss occurred [23]. Ultraprocessed food consumption has also been associated with type 2 diabetes mellitus, another risk factor for an adverse course of COVID-19 infections [24]. Of particular concern is a report suggesting that Chinese patients with obesity who had non-alcoholic fatty liver disease (NAFLD) and were infected with COVID-19 had a six-fold greater risk of COVID-19 infections [25]. Although speculative, diets high in ultra-processed foods may cause both obesity and NAFLD, thereby increasing susceptibility to COVID- 19 .

The combination of a variety of other factors has increased food insecurity. These include poverty, unemployment leading to lost wages, the instability of the food supply, and lack of eligibility, access, or enrollment in federal programs like the Special Supplemental Nutrition Program for Women Infants and Children (WIC), the National School Lunch Program (NSLP), and the Supplemental Nutrition Assistance Program (SNAP). The NSLP and WIC may protect against both obesity and food insecurity [26]. Underlying the disparate interactions of obesity, food insecurity, 
race/ethnicity, and COVID-19 infections are social drivers of health (Fig. 1) [27••]. Structural racism, including inequities in housing, food costs and availability, poverty, and reduced access to health care likely act in a synergistic fashion to increase susceptibility to COVID-19, obesity, and food insecurity. The reason that COVID-19 infections in children and adolescents do not reflect the same disparities seen in adults may be a consequence of a more limited exposure to these deeper drivers by virtue of age. Likewise, the absence of differences in mortality between Black and white Kaiser Permanente members may reflect more equal access to care with a reduction in obesity-associated co-morbidities [28].

\section{Impact of COVID-19 on Essential Workers in the Food Supply Chain}

The effects of the COVID-19 pandemic on the food and agriculture system illustrate the vulnerability of the industrialized food system and the disproportionate impact of the pandemic on the workforce essential to the food supply chain. The US food system is composed of many different sectors that make up over $10 \%$ of US employment [29]. The COVID-19 pandemic has disrupted each step of the food supply chain, from food production to how food is distributed, processed, marketed, purchased, consumed, and ultimately disposed of $[30,31]$.

Food preparers and servers account for 5.6\% of all workers in the USA and are more likely to lack health insurance and have high housing costs, and $41 \%$ are low income [32].
Table 2 Characteristics of animal slaughtering and processing workers in the top five meatpacking and poultry processing states [33]

\begin{tabular}{lll}
\hline Race/ethnicity & Meat packing & Poultry processing \\
\hline White & $29.2 \%$ & $29.5 \%$ \\
Black & $12.0 \%$ & $37.2 \%$ \\
Latinx & $47.7 \%$ & $26.5 \%$ \\
Other & $11.1 \%$ & $6.8 \%$ \\
Foreign born & $56.1 \%$ & $28.1 \%$ \\
Median wage & $\$ 35,000$ & $\$ 26,449$ \\
Below poverty line & $5.6 \%$ & $11.4 \%$ \\
\hline
\end{tabular}

Workers in the food processing sector comprise more than $1 \%$ of non-farm employment in the USA with a majority working in meat-packing and poultry processing plants [29]. Within this sector, Black and Hispanic individuals make up $21.9 \%$ and $34.9 \%$ of the workforce, respectively, compared to $11.3 \%$ and $16.8 \%$ in the entire US workforce [32]. As Table 2 shows, the composition of the workforce differs within the sector. A greater percentage of those working in meat-packing facilities are Latinx and foreign born, whereas Blacks account for a greater proportion of the workers in poultry processing plants [33].

High rates of COVID-19 infections have been observed in the agricultural workforce. For example, over $30 \%$ of workers in a meat-packing plant in Nebraska had polymerase chain reaction confirmed infections [34]. Similar findings were obtained among farmworker employees who packed and sorted fruit [35]. According to a recent CDC study of confirmed COVID-19 infections in the food production

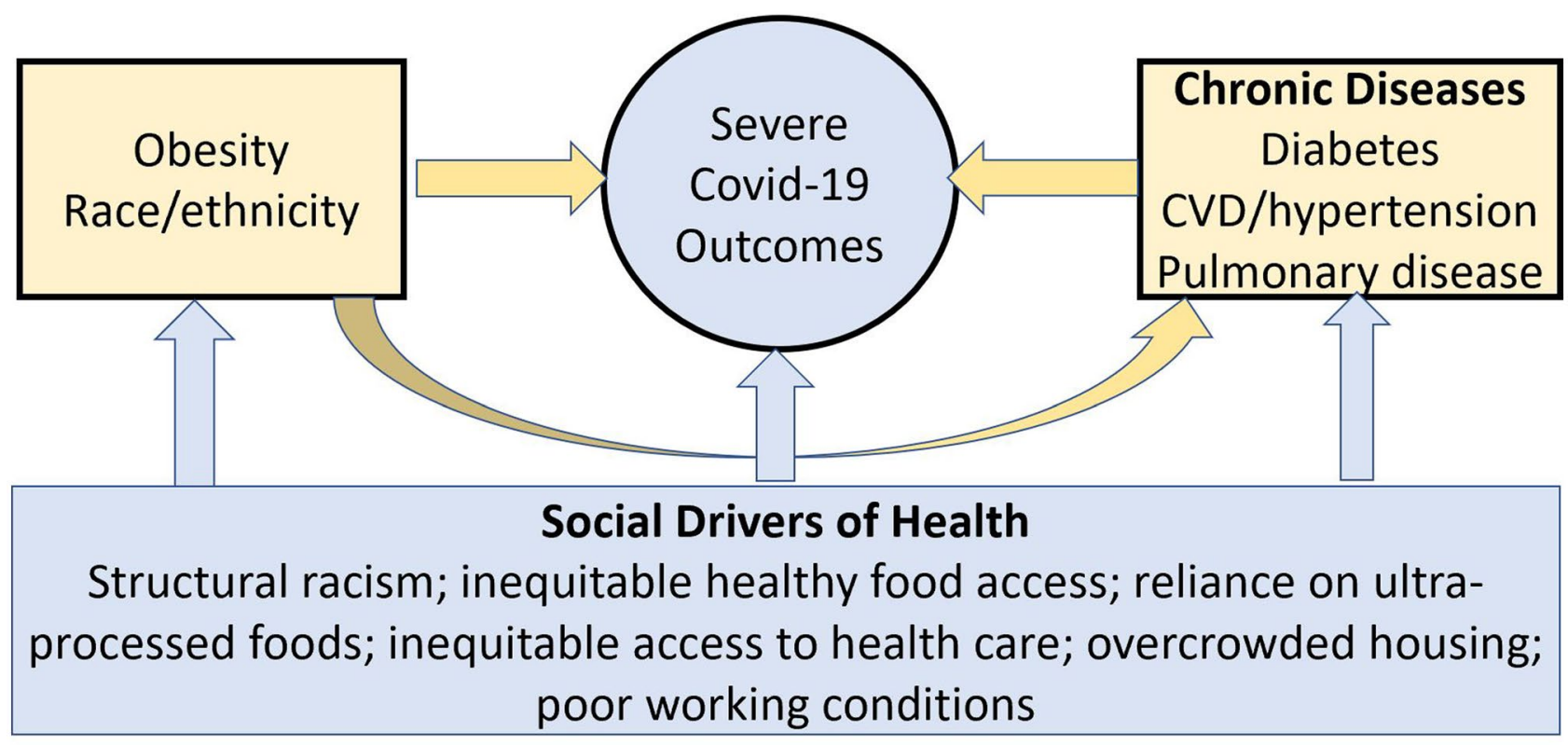

Belanger MJ, Hill MA, Angelidi AM, Dalamaga M, Sowers JR, Mantzoros CS. Covid-19 and Disparities in Nutrition and Obesity. N Engl J Med. 2020;383(11):e69.

Fig. 1 Underlying the disparate interactions of obesity, food insecurity, race/ethnicity and COVID-19 infections are social drivers of health 
sector, $73 \%$ of infections occurred in Hispanic individuals, despite comprising $35 \%$ of the workforce [36]. The lack of personal protective equipment (PPE), lack of spacing between workers, and workers who come to work ill because they cannot afford to miss work have been contributing factors [36, 37].

Despite being deemed "essential" during the pandemic, workers along the food supply chain have been historically underpaid and underappreciated and lacked the benefits necessary for a secure livelihood [38]. Immigrant workers, particularly those who are undocumented, experience workrelated inequities, including lack of health insurance [39]. These populations are further marginalized by a lack of work authorization, causing fear of job loss, job-related violence, and deportation, all of which inhibit workers, their families, and the communities in which they reside from advocating for improvements to their working conditions [40]. The Affordable Care Act, despite its success in expanding insurance coverage across the USA, further marginalizes these same workers, by excluding temporary and undocumented workers from the marketplace subsidies provided to others in this workforce [41]. Further, Temporary Agricultural Workers Visas, or H-2As, allow foreign workers to come to the USA to fill gaps and support labor shortages. Nonetheless, the program suppresses wages for workers in these sectors and has subjected them to a number of human rights violations [40].

\section{Disrupted Food Supply Chain}

COVID-19 exposed the vulnerabilities and inequities of the US food supply chain and its workforce, and disrupted the industrialized food system. It was predicted that these lowwage workers would experience the biggest loss by share of wage with much of this workforce having a remote labor index of 0 , on a scale of 0 to 1 , indicating that none of their work activities can be done at home [42]. In meat processing, high local infection rates caused an increase in absenteeism and unemployment [43]. The heightened risk of infection among farmworkers, driven by close working and living conditions and poor health benefits, greatly jeopardized the continuity of the nation's food supply [44]. From the onset of the pandemic, workers in food manufacturing and processing positions were not given adequate protections related to COVID-19 as well as more general protections like health care, which many workers already lacked [38]. As a result, numerous food-processing plants became COVID-19 hot spots, resulting in a disproportionate number of infections and deaths among people of color, who were already overrepresented in the food processing workforce [37, 45]. A number of plants closed as a result of these outbreaks [46], disrupting the livelihoods of workers and their families [38], and creating bottlenecks along the food supply chain [30].

The meat industry is highly consolidated, contributing to the high rates of infections and consequent absenteeism which disrupted the food supply chain and caused significant food shortages during the COVID-19 pandemic [46]. The food shortages led to increased prices, high rates of food loss, increased reliance on food banks, and ultra-processed foods throughout the country and disproportionally affected people of color $[42,47]$. Food insecurity rates of $50-82 \%$ have previously been reported among seasonal farmworkers [48, 49], and it seems likely that the consequences of COVID-19 may have the same effect on the meatpacking workforce.

\section{Examples of Triple Duty Solutions to the Syndemic of COVID-19, Food Insecurity, and Obesity}

We propose triple duty solutions that will collectively reduce food insecurity, reduce or mitigate obesity, and improve immune responsiveness to minimize the impact of the COVID-19 pandemic, in terms of both prevention and severity of illness, with a particular focus on the essential workforce in the food supply chain. Reducing and preventing food insecurity will decrease the prevalence of obesity, which is a major risk factor for severe infection and death related to COVID-19. Reductions in obesity will simultaneously decrease the frequency and severity of COVID-19 infections in the same populations [3].

\section{Strategies to Increase Food Security}

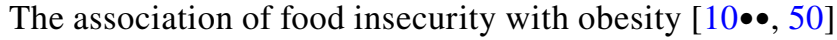
may be partially attributable to inconsistent dietary patterns [51], including increased consumption of ultra-processed foods, which is higher in low-income populations who often rely on food assistance programs such as SNAP. Increasing the federal minimum wage, as proposed in the American Rescue Plan under the Biden Administration [52], is a highly promising strategy to combat food insecurity in the USA. Higher wages will increase economic stability for families [53], thereby enabling individuals and households to purchase more food and afford healthier options that were inaccessible at a lower wage [47]. Expanding social safety net programs, including SNAP and refundable tax credits, is a second strategy aimed at increasing household food security $[54,55]$. Throughout the pandemic, relief packages have increased total SNAP allotments and lowered the risk of food insecurity for many children and families [56, 57]. Maintaining the 
increase in SNAP benefits will help millions of Americans afford foods that more closely align with the USDA Dietary Guidelines [58]. Strengthening these safety net programs by diversifying where benefits are accepted and incentivizing the purchase of unprocessed, locally produced foods, also has a potential impact far beyond the scope of the pandemic [56, 59]. These safety net reforms could increase food security and decrease obesity through healthier diets. Additional safety net programs, including the NSLP and WIC, improve food intake and dietary patterns of low-income children and adolescents, and both have been associated with a decrease in obesity among participants [26].

\section{Strategies Specific to the Essential Workforce in the Food Supply Chain}

As we have shown, COVID-19 has drastically disrupted the livelihoods of many individuals and families around the country, including workers along the food supply chain $[38,60]$. Before and throughout the pandemic, a lack of worker protections led to disproportionate rates of infection in this essential workforce [34, 35]. Essential workers in the food supply chain like those in meat-packing often lack health insurance, hazard pay, paid sick leave, and a living wage $[38,40]$. Collectively, these protections would have reduced the COVID-19 outbreaks that resulted from close working conditions and the fear of job loss associated with a lack of hazard pay or paid sick leave [61]. Employees who came to work despite symptomatic infections directly affected the lives of coworkers and their families, an indirect consequence of poor worker protections. Similarly, workers with health insurance may have felt more confident seeking medical care, thereby decreasing the burden of infection on their communities. Extending union membership to non-citizen workers provides a strategy for improving and expanding worker protections for all workers along the food supply chain, including undocumented workers who are more vulnerable, yet essential, to sustaining the country's food supply $[62,63]$. Likewise, reform of non-citizen worker programs such as the H-2A Guestworker Program would provide these essential workers, who comprise $10 \%$ of crop farmworkers in the USA, with protections and an equitable wage [40,64]. Union membership could increase pressure to provide PPE, lower the fear of job loss, enable workers to stay home if symptomatic, and potentially lower the spread of COVID-19 in their workspaces and communities [61]. Increased wages associated with union membership would also increase food security and reduce or mitigate obesity. All of these strategies could independently and collectively yield a stronger and healthier workforce for our food system by protecting the individuals who protect our food supply.

\section{Politicization and Policy Resistance}

Shortly after initial plant closures due to COVID-19 infections, President Trump issued a Presidential Executive Order delegating plant closure and reopening to government entities, ultimately requiring that operations continue to prevent a disruption in the food supply chain, despite the threat of infection to meat-packing workers $[65,66]$. The Trump Administration prioritized food system stabilization and profit over the health of the workforce in a number of instances. In the first stimulus bill, the Families First Coronavirus Response Act (FFCRA) [67], which exempted employers with greater than 500 employees from requiring paid sick leave, left many workers along the food supply chain without paid sick leave, unable to take time off, and made them more likely to come to work infected with or exposed to COVID-19 [44]. The FFCRA also channeled about US $\$ 14$ billion through the Commodity Credit Corporation (CCC) to be used at the discretion of the Secretary of Agriculture, who distributed most of these funds to industry and large-scale producers [68], highlighting the consolidation within the food system, particularly among commodity crops [69]. Because little aid reached those most at risk, profit again was prioritized over health. This pattern of deliberate neglect continued through the end of the Trump administration, including a last-minute effort to increase processing speeds despite compelling data demonstrating the high prevalence of COVID-19 infections, and high injury rates among line workers [36, 70,71]. These observations illustrate the politicization of the food-processing industry and how policies capitalized on and fostered racial inequities [72]. These observations also emphasize the need for unionization of the food-processing workforce as the first step in generating the political will necessary to address these inequities.

\section{Examples of Solutions to the Twin Syndemics}

As Mark Bittman has stated "You can't talk about agriculture without talking about the environment. You can't talk about animal welfare without talking about the welfare of food workers, and you can't talk about food workers without talking about income inequality, racism, and immigration." [73]. In the first of our two papers, we describe how the food and agriculture environment contributes to the Global Syndemic of Obesity, Undernutrition, and Climate 
Change, with a particular focus on meat production. As this paper has pointed out, meat production is also at the heart of the COVID-19, Obesity, and Food Insecurity Syndemic. Strengthening local and regional food systems can dismantle obesogenic environments, promote sustainable plant-based diets, and provide opportunities for employment, a living wage, and worker protections. Therefore, strengthening local and regional food systems can act as a solution to simultaneously address both syndemics.

Local and regional food systems are more agile and resilient compared to the current industrialized food chain [74], and could provide protection during times of crisis, such as the COVID-19 pandemic. The COVID-19 pandemic demonstrated the rigidity of the food supply chain when worker illness closed processing plants, creating logistic bottlenecks and increasing prices and food loss [75]. Local food systems could potentially prevent worker illness and plant closures by increasing the number of diversified and smaller producers. Local and regional food systems also aim to disincentivize consolidation along the food supply chain, which could prevent logistic bottlenecks as a major vulnerability to the country's food supply [30]. Avoiding consolidation, which contributes to poorer-quality diets and negative environmental impacts, also prioritizes human and planetary health [76]. On the demand side, the agility of a local food system could have reduced food insecurity during the pandemic by allowing food to be re-routed from restaurants to grocery stores or other distribution sources to meet the demand for food at home [77], preventing the increase in food prices that decreased food access [47], and the reliance on food banks [77]. Stabilization of the food supply chain could reduce food insecurity, improve nutritional status, and thereby improve resistance to COVID-19 infections and reduce obesity. Stronger local and regional food systems can also counter structural racism and the resulting inequities in opportunity and health outcomes among individuals of color, many of whom are our nation's essential food system workers $[78,79]$.

\section{Strategies to Strengthen Sustainable Local and Regional Food Systems}

Strategies to strengthen local and regional food systems include city initiatives and state-level legislation, illustrated by the two models discussed below. Systems-oriented initiatives and legislation at the city- and state-level provide models for building sustainable food systems to promote plant-based diets [80] and increase the resiliency of our food supply. One such model is the District of Columbia's proposal for a Central Food Processing Facility (CFPF) [81]. The core functions of this facility are to use fresh and locally sourced ingredients to feed local institutions; provide aggregation, storage, and comanufacturing space for small food businesses and regional farms; and create workforce development opportunities in the food sector. Through these system-level adjustments, the CFPF model can act as a triple-duty solution by combating undernutrition and obesity, both of which would decrease the impact of the COVID-19 pandemic, through better diet quality and supporting nutritional standards throughout local organizations and institutions. Localizing the food supply will also reduce obesity by increasing food security and improving access to healthier, minimally processed foods, thus reducing the reliance on ultra-processed foods [82]. Cost acts as the primary barrier to healthy foods for low-income populations [47]. Increased coordination will enable the CFPF to act as a broker between producers and consumers, regulating food prices to increase the accessibility of healthier foods and improving food security and nutrition, and reducing obesity [76]. The CFPF model also creates local jobs which could reduce obesity and food insecurity by increasing employment and wages as well as decreasing greenhouse gas (GHG) emissions by locating the CFPF in close proximity to public transportation $[83,84]$. The CFPF also provides storage and preservation facilities which can reduce the environmental impact of food waste [85]. These environmental considerations in addition to the aforementioned strategies make the case for CFPF as a solution to the Global Syndemic of Undernutrition, Obesity, and Climate Change.

The Equitable Economic Recovery, Healthy Food Access, Climate Resilient Farms \& Worker Protection Bond Act [86], introduced in March of 2021, is an example of statelevel legislation focused on improving the resiliency of local and regional food systems within California. As the name suggests, the legislation aims to protect workers, increase the use of sustainable and climate-resilient farming practices, create and restore jobs, and increase food security [87]. The effects of this legislation benefit people and the planet, including sustainable practices, diversity in food production, local availability of fresh foods, and promotion of equity by moving aid from large-scale to small-scale, underrepresented producers, and distributors [88-91]. The legislation also directs a minimum of $40 \%$ of the funding to projects in low-income communities and to historically disadvantaged farmers and ranchers. This funding could play a role in reducing obesity by prioritizing community initiatives related to healthy eating [80]. Such legislation can act as a solution to the syndemic of COVID-19, Obesity, and Food Insecurity by mitigating and preventing obesity and undernutrition, both of which would decrease the impact of the COVID-19 pandemic, by incentivizing plant-based diets, increasing the availability of fresh, healthy foods, and increasing food security. This legislation could also act as a solution to the Global Syndemic of Undernutrition, Obesity, and Climate Change by limiting GHG emissions and 
other environmental impacts through the use of sustainable farming practices [90] in addition to the aforementioned strategies.

\section{Implications for Structural Racism and Food Sovereignty}

Structural racism on the county-level and systemic inequalities [92••], largely attributable to the racism of US institutions [93], have been associated with obesogenic environments, such as fewer grocery stores, more corner stores, and more fast-food restaurants [94]. Two policy recommendations for mitigating structural racism include increasing economic empowerment and funding community programs that enhance neighborhood stability [95], both of which can be accomplished with the aforementioned models. Local sustainable food systems also support food sovereignty, defined as "the right of people to determine their own food and agriculture systems, and their right to access affordable, nutritious, healthy, and culturally appropriate food produced through ecologically sound and sustainable methods" [96]. The conditions required for food sovereignty include food access, health equity, fair and living wages, land access, just immigration policy, restraints upon corporations, nonexploitative farm labor conditions, and environmental wellbeing, each of which addresses the COVID-19, Obesity, and Food Insecurity Syndemic.

\section{Conclusions}

The novel Syndemic of COVID-19, Obesity, and Food Insecurity is a consequence of an ossified US food system that propagates unsustainable food production and consumption, and prioritizes profit over health. The COVID-19 pandemic has increased food insecurity. Unsustainable dietary patterns fueled by food insecurity have increased the risk of obesity, which increased the risk of COVID-19-related hospitalization and death. The pandemic has highlighted existing shortcomings along the food supply chain, including consolidation, which incentivizes unsustainable production and consumption, and a lack of protections for the workforce driving it. Susceptibility of the food system's essential workforce to COVID-19 infections is driven by deliberate inequities, including lack of personal protective equipment, food insecurity, poor and congested housing and lack of health care. At the intersection of the new Syndemic of COVID19, Obesity, and Food Insecurity and the Global Syndemic of Obesity, Undernutrition, and Climate Change, the US food system provides an opportunity for systemic reform. We propose strengthening local and regional food systems to simultaneously mitigate the effects of the twin syndemics by stabilizing the food supply chain, lowering GHG emissions, promoting plant-based diets, providing opportunities for employment and a living wage, and incentivizing sustainable agricultural practices. Simultaneously, strengthening local and regional food systems can work to dismantle systems of structural racism, promote food sovereignty, and secure the livelihoods of the food system's workforce and consumers alike.

\section{Declarations}

Human and Animal Rights and Informed Consent This article does not contain any studies with human or animal subjects performed by any of the authors.

\section{References}

Papers of particular interest, published recently, have been highlighted as:

- Of importance

$\bullet$ Of major importance

1. Dietz W, Pryor S. How can we act to mitigate the global syndemic of obesity undernutrition and climate change? Curr Obesity Rep. 2021.

2.• Swinburn BA, Kraak VI, Allender S, Atkins VJ, Baker PI, Bogard JR, et al. The global syndemic of obesity, undernutrition, and climate change: the Lancet Commission report. Lancet. 2019;393(10173):791-846. The pandemics of obesity, undernutrition, and climate change, referred to as The Global Syndemic, occur in the same time, place, and population, simultaneously impact each other and disproportionately affect vulnerable populations.

3. Kompaniyets L, Goodman AB, Belay B, Freedman DS, Sucosky MS, Lange SJ, et al. Body mass index and risk for COVID19-related hospitalization, intensive care unit admission, invasive mechanical ventilation, and death - United States, March-December 2020. MMWR Morb Mortal Wkly Rep. 2021;70(10):355-61.

4.• Kompaniyets L, Agathis NT, Nelson JM, Preston LE, Ko JY, Belay B, et al. Underlying medical conditions associated with severe COVID-19 illness among children. JAMA Netw Open. 2021;4(6):e2111182. Obesity is a major risk factor for COVID19-related hospitalizations in children and adolescents.

5. Centers for Disease Control and Prevention. Risk for COVID-19 infection, hospitalization, and death by race/ethnicity 2021 [cited 2021 June 14]. Available from: https://www.cdc.gov/coronavirus/ 2019-ncov/covid-data/investigations-discovery/hospitalizationdeath-by-race-ethnicity.html.

6. Preston LE, Chevinsky JR, Kompaniyets L, Lavery AM, Kimball A, Boehmer TK, et al. Characteristics and disease severity of US children and adolescents diagnosed with COVID-19. JAMA Netw Open. 2021;4(4):e215298.

7.••Price-Haywood EG, Burton J, Fort D, Seoane L. Hospitalization and mortality among Black patients and White patients with Covid-19. N Engl J Med. 2020;382(26):2534-43. COVID-19 disproportionately impacts Black adult patients compared to white adult patients, likely attributable to higher rates of hypertension, diabetes and obesity. 
8. Mulugeta W, Desalegn H, Solomon S. Impact of the COVID19 pandemic lockdown on weight status and factors associated with weight gain among adults in Massachusetts. Clin Obes. 2021:e12453.

9.••Jenssen BP, Kelly MK, Powell M, Bouchelle Z, Mayne SL, Fiks AG. COVID-19 and changes in child obesity. Pediatrics. $2021 ; 147(5)$. The prevalence of obesity increased among a large sample of pediatric patients in June-December 2020 compared to June-December 2019 with a disproportionately greater impact on youth of color.

$10 \bullet \bullet$ Myers CA, Mire EF, Katzmarzyk PT. Trends in adiposity and food insecurity among US adults. JAMA Netw Open. 2020;3(8):e2012767. The prevalence of food insecurity increased between 1999-2000 and 2015-2016, with disproportionately greater increases among Black and Hispanic individuals, and is highest among individuals with obesity.

11. Gupta P, Gonzalez D, Waxman E. Forty percent of Black and Hispanic parents of school-age children are food insecure, : Urban Institute; 2020 [June 30, 2021]. Available from: https://www. urban.org/research/publication/forty-percent-black-and-hispanicparents-school-age-children-are-food-insecure.

12. Spoede E, Corkins MR, Spear BA, Becker PJ, Gunnell Bellini S, Hoy MK, et al. Food insecurity and pediatric malnutrition related to under- and overweight in the United States: an evidence analysis center systematic review. J Acad Nutr Diet. 2021;121(5):95278 e 4.

13. Wilke J, Mohr L, Tenforde AS, Edouard P, Fossati C, GonzalezGross M, et al. A pandemic within the pandemic? Physical activity levels substantially decreased in countries affected by COVID19. Int J Environ Res Public Health. 2021;18(5).

14. Jia P, Zhang L, Yu W, Yu B, Liu M, Zhang D, et al. Impact of COVID-19 lockdown on activity patterns and weight status among youths in China: the COVID-19 Impact on Lifestyle Change Survey (COINLICS). Int J Obes (Lond). 2021;45(3):695-9.

15. Sallis R, Young DR, Tartof SY, Sallis JF, Sall J, Li Q, et al. Physical inactivity is associated with a higher risk for severe COVID-19 outcomes: a study in 48440 adult patients. Br J Sports Med. 2021.

16. da Silveira MP, da Silva Fagundes KK, Bizuti MR, Starck E, Rossi RC, de Resende E. Silva DT. Physical exercise as a tool to help the immune system against COVID-19: an integrative review of the current literature. Clin Exp Med. 2021;21(1):15-28.

17. Creswell J. 'I just need the comfort': processed foods make a pandemic comeback. New York Times. April 7, 2020.

18. Adams EL, Caccavale LJ, Smith D, Bean MK. Food insecurity, the home food environment, and parent feeding practices in the era of COVID-19. Obesity (Silver Spring). 2020;28(11):2056-63.

19. De Backer C, Teunissen L, Cuykx I, Decorte P, Pabian S, Gerritsen $\mathrm{S}$, et al. An evaluation of the COVID-19 pandemic and perceived social distancing policies in relation to planning, selecting, and preparing healthy meals: an observational study in 38 countries worldwide. Front Nutr. 2020;7:621726.

20. Monteiro CA, Cannon G, Moubarac JC, Levy RB, Louzada MLC, Jaime PC. The UN Decade of Nutrition, the NOVA food classification and the trouble with ultra-processing. Public Health Nutr. 2018;21(1):5-17.

21. Pagliai G, Dinu N, Madarena M, Bonaccio M, Iacoviello L, Sofi F. Consumption of ultra-processed foods and health status: a systematic review and meta-analysis. Br J Nutr. 2021;125(3):308-18.

22. Chang K, Khandpur N, Neri D, Touvier M, Huybrechts I, Millett $\mathrm{C}$, et al. Association between childhood consumption of ultraprocessed food and adiposity trajectories in the Avon Longitudinal Study of Parents and Children Birth Cohort. JAMA Pediatr. 2021:e211573.

23. Hall KD, Ayuketah A, Brychta R, Cai H, Cassimatis T, Chen KY, et al. Ultra-processed diets cause excess calorie intake and weight gain: an inpatient randomized controlled trial of ad libitum food intake. Cell Metab. 2019.

24. Srour B, Fezeu LK, Kesse-Guyot E, Alles B, Debras C, DruesnePecollo N, et al. Ultraprocessed food consumption and risk of type 2 diabetes among participants of the NutriNet-Sante Prospective Cohort. JAMA Intern Med. 2020;180(2):283-91.

25. Zheng KI, Gao F, Wang XB, Sun QF, Pan KH, Wang TY, et al. Letter to the Editor: obesity as a risk factor for greater severity of COVID-19 in patients with metabolic associated fatty liver disease. Metabolism. 2020;108:154244.

26. Dietz WH. Better diet quality in the Healthy Hunger-Free Kids Act and WIC Package reduced childhood obesity. Pediatrics. 2021;147(4).

27.••Belanger MJ, Hill MA, Angelidi AM, Dalamaga M, Sowers JR, Mantzoros CS. Covid-19 and disparities in nutrition and obesity. N Engl J Med. 2020;383(11):e69. Racial and ethnic disparities in nutrition, obesity, and COVID-19 are driven by socioeconomic, educational, and environmental disadvantages faced by communities of color.

28. Tartof SY, Qian L, Hong V, Wei R, Nadjafi RF, Fischer H, et al. Obesity and mortality among patients diagnosed with COVID-19: results from an integrated health care organization. Ann Intern Med. 2020;173(10):773-81.

29. Ag and Food Sectors and the Economy: USDA Economic Research Service; 2021 [July 21, 2021]. Available from: https:// www.ers.usda.gov/data-products/ag-and-food-statistics-chartingthe-essentials/ag-and-food-sectors-and-the-economy/.

30. Felix I, Martin A, Mehta V, Mueller C. US food supply chain: disruptions and implications from COVID-19: McKinsey \& Company; 2020 [July 21, 2021]. Available from: https://www. mckinsey.com/ /media/McKinsey/Industries/Consumer\% 20Packaged\%20Goods\% 20/Our\%20Insights/US\%20food\% 20supply\%20chain\%20Disruptions\%20and\%20implications\% 20from\%20COVID\%2019/US-food-supply-chain-Disruptionsand-implications-from-COVID-19-vF.pdf.

31. Mather M, Jarosz B. Workers at risk during the Coronavirus pandemic: four in 10 food preparers and servers are low-income: Population Reference Bureau; 2020 [July 21, 2021]. Available from: https:// www.prb.org/resources/workers-at-risk-during-the-coronaviruspandemic-four-in-10-food-preparers-and-servers-are-low-income/.

32. Artiga A, Rae M. The COVID-19 outbreak and food production workers: who is at risk? 2020 [cited 2021 June 11]. Available from: https://www.kff.org/coronavirus-covid-19/issue-brief/thecovid-19-outbreak-and-food-production-workers-who-is-at-risk/.

33. Steusse A, Dollar N. Who are America's meat and poultry workers? 2020 [cited 2021 June 11]. Available from: https://www.epi. org/blog/meat-and-poultry-worker-demographics/.

34. Donahue M, Sreenivasan N, Stover D, Rajasingham A, Watson J, Bealle A, et al. Notes from the field: characteristics of meat processing facility workers with confirmed SARS-CoV-2 infection - Nebraska, April-May 2020. MMWR Morb Mortal Wkly Rep. 2020;69(31):1020-2.

35. Miller JS, Holshue M, Dostal TKH, Newman LP, Lindquist S. COVID-19 outbreak among farmworkers - Okanogan County, Washington, May-August 2020. MMWR Morb Mortal Wkly Rep. 2021;70(17):617-21.

36. Waltenburg MA, Victoroff T, Rose CE, Butterfield M, Jervis RH, Fedak KM, et al. Update: COVID-19 among workers in meat and poultry processing facilities - United States, April-May 2020. MMWR Morb Mortal Wkly Rep. 2020;69(27):887-92.

37. Dyal JW, Grant MP, Broadwater K, Bjork A, Waltenburg MA, Gibbins JD, et al. COVID-19 among workers in meat and poultry processing facilities - 19 States, April 2020. MMWR Morb Mortal Wkly Rep. 2020;69(18). 
38. Chappelear K. Essential food system workers: essential farm workers: Johns Hopkins Berman Institute of Bioethics; 2021 [July 21, 2021]. Available from: https://bioethics.jhu.edu/research-and-outreach/covid19-bioethics-expert-insights/essential-workers-project/essential-foodsystem-workers/.

39. Health Coverage of Immigrants: Kaiser Family Foundation; 2021 [July 21, 2021]. Available from: https://www.kff.org/ racial-equity-and-health-policy/fact-sheet/health-coverage-ofimmigrants/.

40. Fitch C, Hricko, C, Martin, R. Public health, immigration reform, and food system change. . Baltimore, Maryland: Johns Hopkins Center for a Livable Future, 2017.

41. Schenker M, McCurdy S, Riden H, Villarejo D. Improving the health of agricultural workers and their families in California: University of California Global Health Institute; 2015 [July 21, 2021]. Available from: https://ucghi.universityofcalifornia.edu/ sites/default/files/ucghi-ag-work-paper-2015.pdf.

42. del Rio-Chanona RM, Mealy P, Pichler A, Lafond F, Farmer JD. Supply and demand shocks in the COVID-19 pandemic: an industry and occupation perspective. Oxford Review of Economic Policy. 2020;36(Supplement_1):S94-S137.

43. Cho S, Lee J, Winters J. COVID-19 employment status impacts on food sector workers economics working papers: Iowa State University Department of Economics; 2020 [July 21, 2021]. Available from: https://lib.dr.iastate.edu/cgi/viewcontent.cgi?article $=1107 \&$ context=econ_workingpapers.

44. Eskenazi B, Mora A, Lewnard J, Cuevas M, Nkowcha O. Prevalence and predictors of SARS-COV-2 infection among farmworkers in Monterey County, CA: UC Berkeley School of Public Health; 2020 [July 21, 2021]. Available from: https://cerch.berkeley.edu/sites/ default/files/ucb_csvs_white_paper_12_01_20_final_compressed. pdf.

45. Soucheray S. US food processing plants become COVID-19 hot spots University of Minnesota: Center for Infectious Disease Research and Policy; 2020 [July 21, 2021]. Available from: https://www.cidrap.umn.edu/news-perspective/2020/04/us-foodprocessing-plants-become-covid-19-hot-spots.

46. Ramsey A, Goodwin B, Haley M. Labor dynamics and supply chain disruption in food manufacturing: National Bureau of Economic Research; 2021 [July 21, 2021]. Available from: https:// www.nber.org/papers/w28896.

47. Alkon A, Block D, Moore K, Gillis C, DiNuccio N, Chaves N. Foodways of the urban poor. Geoforum. 2013;48:126-35.

48. Quandt SA, Arcury TA, Early J, Tapia J, Davis JD. Household food security among migrant and seasonal Latino farmworkers in North Carolina. Public Health Rep. 2004;119(6):568-76.

49. Weigel MM, Armijos RX, Hall YP, Ramirez Y, Orozco R. The household food insecurity and health outcomes of U.S.-Mexico border migrant and seasonal farmworkers. J Immigr Minor Health. 2007;9(3):157-69.

50. Nettle D, Andrews C, Bateson M. Food insecurity as a driver of obesity in humans: the insurance hypothesis. Behavioral and Brain Sciences. 2017;40:e105.

51. Castner L, Wakar B, Wroblewska K, Trippe C, Cole N. Benefit redemption patterns in the supplemental nutrition assistance program in fiscal year 2017 USDA Food and Nutrition Service: Insight Policy Research; 2020 [July 21, 2021]. Available from: https://www.fns.usda.gov/snap/benefit-redemption-patterns-fy2017\#: : text $=$ On $\% 20$ average $\% 2 \mathrm{C} \% 20$ SNAP $\% 20$ households $\%$ 20had,before $\% 20$ receiving $\% 20$ their\%20next $\% 20$ issuance.

52. Fact Sheet: The American Families Plan: The White House Briefing Room; 2021 [July 21, 2021]. Available from: https://www. whitehouse.gov/briefing-room/statements-releases/2021/04/28/ fact-sheet-the-american-families-plan/.

53. Leigh J, Du J. Effects of minimum wages on population health: Health Affairs Health Policy Brief; 2018. Available from: https:// www.healthaffairs.org/do/https://doi.org/10.1377/hpb20180622. 107025/full.

54. Keith-Jennings B, Llobrera J, Dean S. Links of the supplemental nutrition assistance program with food insecurity, poverty, and health: evidence and potential. Am J Public Health. 2019;109(12):1636-40.

55. Waxman S, Sherman A, Cox K. Income support associated with improved health outcomes for children, many studies show: center on budget and policy priorities; 2021 [July 21, 2021]. Available from: https://www.cbpp.org/sites/default/files/5-27-21tax.pdf.

56. Rosenbaum D, Neuberger Z, Keith-Jennings B, Nchako C. Food assistance in American Rescue Plan Act will reduce hardship, provide economic stimulus: center on budget and policy priorities; 2021 [July 21, 2021]. Available from: https://www.cbpp.org/ research/food-assistance/food-assistance-in-american-rescueplan-act-will-reduce-hardship-provide.

57. Tracking the COVID-19 Recession's effects on food, housing, and employment hardships 2021 [July 21, 2021]. Available from: https://www.cbpp.org/research/poverty-and-inequality/trackingthe-covid-19-recessions-effects-on-food-housing-and.

58. Carlson S, Llobrera J, Keith-Jennings B. More adequate SNAP benefits would help millions of participants better afford food: center on budget and policy priorities; 2021 [July 21, 2021]. Available from: https://www.cbpp.org/research/food-assistance/more-adequatesnap-benefits-would-help-millions-of-participants-better\#: :text= Raising $\% 20$ SNAP $\% 20$ benefits $\% 20$ could $\% 20$ improve $\% 20$ the $\%$ 20nutritional $\% 20$ quality, between $\% 20$ SNAP $\% 20$ benefits $\% 2 \mathrm{C} \%$ 20 food $\% 20$ spending $\% 2 \mathrm{C} \% 20$ and $\% 20$ diet $\% 20$ quality.

59. Mozaffarian D, Liu J, Sy S, Huang Y, Rehm C, Lee Y, et al. Costeffectiveness of financial incentives and disincentives for improving food purchases and health through the US Supplemental Nutrition Assistance Program (SNAP): A microsimulation study. PLOS Medicine. 2018;15(10).

60. Parks C, Nugent N, Fleischhacker S, Yaroch A. Food system workers are the unexpected but under protected COVID heroes. J Nutr. 2020;150(8):2006-8.

61. Packing and Processing Union: The United Food and Commercial Workers International Union (UFCW); 2021 [July 21, 2021]. Available from: https://www.ufcw.org/who-we-represent/packingand-processing/.

62. To Safeguard the US Food Supply Chain During the Covid-19 Pandemic, We Must Protect Food and Agricultural Workers: Recommendations for Policymakers and Employers: Johns Hopkins Center for a Livable Future; 2020 [July 21, 2021]. Available from: https://clf.jhsph.edu/publications/safeguard-us-food-supply-chainduring-covid-19-pandemic-we-must-protect-food-and.

63. Kerwin D, Nicholson M, Alulema D, Warren R. US foreign-born essential workers by status and state, and the global pandemic: the Center for Migration Studies of New York (CMS); 2020 [July 21, 2021]. Available from: https://cmsny.org/wp-content/uploads/ 2020/05/US-Essential-Workers-Printable.pdf.

64. Costa D, Martin P. Coronavirus and farmworkers: Economic Policy Institute; 2020 [July 21, 2021]. Available from: https://www. epi.org/publication/coronavirus-and-farmworkers-h-2a/.

65. Colvin J. Trump orders meat processing plants to remain open: The Associated Press; 2020 [July 21, 2021]. Available from: https://apnews.com/article/south-dakota-donald-trump-us-newsap-top-news-virus-outbreak-67cb4bad7ffe500beabdf8e7e7efea5d.

66. Stabenow D. Food Supply Chain Letter: United States Senate 2020 [July 21, 2021]. Available from: https://www.agriculture.senate. gov/imo/media/doc/20.04.20\%20Food\%20Supply\%20Chain\% 20Letter.pdf.

67. Families First Coronavirus Response Act: Employee Paid Leave Rights: U.S. Department of Labor; 2020 [July 21, 2021]. Available from: https://www.dol.gov/agencies/whd/pandemic/ffcraemployee-paid-leave. 
68. Waterman C, Davidson J. COVID-19 Stimulus: bailout for corporate agribusiness or a lifeline for our food system? : Food Tank; 2020 [July 21, 2021]. Available from: https://foodtank.com/news/ 2020/04/covid-19-stimulus-bailout-for-corporate-agribusinessor-a-lifeline-for-our-food-system/.

69. MacDonald J, Hoppe R. Examining consolidation in U.S. agriculture: USDA Economic Research Service; 2018 [July 21, 2021]. Available from: https://www.ers.usda.gov/amber-waves/2018/ march/examining-consolidation-in-us-agriculture/.

70. McConnell M. "When we're dead and buried, our bones will keep hurting": Human Rights Watch; 2019 [July 21, 2021]. Available from: https://www.hrw.org/report/2019/09/04/when-were-dead-andburied-our-bones-will-keep-hurting/workers-rights-under-threat.

71. Kindy K, Mellnik T, Hernandez A. The Trump administration approved faster line speeds at chicken plants. Those facilities are more likely to have covid-19: The Washington Post; 2021 [July 21, 2021]. Available from: https://www.washingtonpost.com/politics/ trump-chicken-covid-coronavirus-biden/2021/01/03/ea8902b03a39-11eb-98c4-25dc9f4987e8_story.html.

72. Salerno C, Arena O. How COVID-19 food chain relief can build a more equitable food system for workers: Urban Institute; 2020 [July 21, 2021]. Available from: https://www.urban.org/urbanwire/how-covid-19-food-chain-relief-can-build-more-equitablefood-system-workers.

73. Bittman M. Animal, vegetable, junk: a history of food, from sustainable to suicidal: Mariner Books; 2021.

74. Huff AG, Beyeler WE, Kelley NS, McNitt JA. How resilient is the United States' food system to pandemics? J Environ Stud Sci. 2015;5(3):337-47.

75. Ellison B, Kalaitzandonakes M. Food Waste and Covid-19: Impacts along the Supply Chain farmdoc daily: Department of Agriculture and Consumer Economics, University of Illinois; 2020 [July 21, 2021]. Available from: https://farmdocdaily.illinois.edu/2020/09/ food-waste-and-covid-19-impacts-along-the-supply-chain.html.

76. Committee on a Framework for Assessing the Health E, and Social Effects of the Food System, Board FaN, Resources BoAaN, Medicine Io, Council NR. Social and Economic Effects of the U.S. Food System. A framework for assessing effects of the food system: National Academies Press (US); 2015.

77. Welsh C. Covid-19 and the U.S. Food System: Center for Strategic and International Studies (CSIS); 2020 [July 21, 2021]. Available from: https://www.csis.org/analysis/covid-19-and-us-food-system.

78. Odoms-Young A, Bruce MA. Examining the impact of structural racism on food insecurity: implications for addressing racial/ethnic disparities. Fam Community Health. 2018;41 Suppl 2 Suppl, Food Insecurity and Obesity(Suppl 2 FOOD INSECURITY AND OBESITY):S3-S6.

79. Bailey ZD, Krieger N, Agénor M, Graves J, Linos N, Bassett MT. Structural racism and health inequities in the USA: evidence and interventions. Lancet. 2017;389(10077):1453-63.

80. Barnhill A, Palmer A, Weston CM, Brownell KD, Clancy K, Economos CD, et al. Grappling with complex food systems to reduce obesity: a US public health challenge. Public Health Rep. 2018;133(1_suppl):44S-53S.

81. Cureate, Group TFW. Full assessment of a central food processing facility for Washington, DC: District of Columbia Office of Planning; 2021 [July 21, 2021]. Available from: https://dcfoodpolicycouncilorg. files.wordpress.com/2021/06/cpf_assessment_full_report_final.pdf? $\mathrm{mc}$ cid $=8 \mathrm{c} 57 \mathrm{~d} 325 \mathrm{ae} \& \mathrm{mc}$ eid $=1 \mathrm{fdbdeceec}$.

82. Organization PAH, Organization WH. Ultra-processed food and drink products in Latin America: trends, impact on obesity, policy implications 2015 [July 21, 2021]. Available from: https://iris. paho.org/bitstream/handle/10665.2/7699/9789275118641_eng. pdf.

83. Ogden CL, Fakhouri TH, Carroll MD, Hales CM, Fryar CD, Li X, et al. Prevalence of obesity among adults, by household income and education - United States, 2011-2014. MMWR Morb Mortal Wkly Rep. 2017;66(50):1369-73.

84. Xiao C, Goryakin Y, Cecchini M. Physical activity levels and new public transit: a systematic review and meta-analysis. Am J Prev Med. 2019;56(3):464-73.

85. Willett W, Rockström J, Loken B, Springmann M, Lang T, Vermeulen S, et al. Food in the Anthropocene: the EAT-Lancet Commission on healthy diets from sustainable food systems. Lancet. 2019;393(10170):447-92.

86. Rivas R. Equitable economic recovery, healthy food access, climate resilient farms, and Worker Protection Bond Act of 2022: California Assembly; 2021 [July 21, 2021]. Available from: https://legiscan.com/CA/sponsors/AB125/2021.

87. Brook L, Sharma A. Chance for a more resilient and equitable food system in CA: Natural Resources Defense Council (NRDC); 2021 [July 21, 2021]. Available from: https://www.nrdc.org/experts/ lena-brook/chance-more-resilient-and-equitable-food-system-ca.

88. Raymond B. Sustainable food: a conversation with Jamie Harvie-executive director, institute for a sustainable future. Perm J. 2010;14(1):70-7.

89. Allen T, Prosperi P, Cogill B, Flichman G. Agricultural biodiversity, social-ecological systems and sustainable diets. Proc Nutr Soc. 2014;73(4):498-508.

90. Fanzo J, Bellows AL, Spiker ML, Thorne-Lyman AL, Bloem MW. The importance of food systems and the environment for nutrition. Am J Clin Nutr. 2020;113(1):7-16.

91. Gyawu R, Quansah JE, Fall S, Gichuhi PN, Bovell-Benjamin AC. Community food environment measures in the Alabama Black Belt: implications for cancer risk reduction. Prev Med Rep. 2015;2:689-98.

$92 \bullet \bullet B l e i c h$ SN, Ard JD. COVID-19, Obesity, and structural racism: understanding the past and identifying solutions for the future. Cell Metab. 2021;33(2):234-41. Structural racism and associated systemic inequities, such as unequal access to healthcare, housing, education, and employment, play a significant role in racial disparities in both obesity and COVID-19.

93. Williams DR, Priest N, Anderson NB. Understanding associations among race, socioeconomic status, and health: patterns and prospects. Health Psychol. 2016;35(4):407-11.

94. Bell C, Kerr J, Young J. Associations between obesity, obesogenic environments, and structural racism vary by county-level racial composition. International Journal of Environmental Research and Public Health. 2019;16(5).

95. Egede LE, Walker RJ. Structural racism, social risk factors, and Covid-19 - a dangerous convergence for Black Americans. N Engl J Med. 2020;383(12):e77.

96. Ayazi H, Elsheikh E. The U.S. Farm Bill: corporate power and structural racialization in the United States Food System University of California, Berkeley: Haas Institute for a Fair and Inclusive Society; 2015 [July 21, 2021]. Available from: https://www.academia.edu/ 18941323/The_U_S_Farm_Bill_Corporate_Power_and_Structural_ Racialization_in_the_United_States_Food_System_2015_.

Publisher's Note Springer Nature remains neutral with regard to jurisdictional claims in published maps and institutional affiliations. 